\title{
A SAÚdE DA GESTANTE *
}

* * Anne Lore Martha Tröger

RBEh/04

TROGER, A.L.M. - A saúde da gestante. Rev. Bras, Enf.; DF, 32 : 255-258, 1979.

A "Declaração Universal dos Direitos do Homem", aprovada e proclamada em resolução na III Sessão ordinária da Assembléia Geral das Naçōes Unidas, a 10 de dezembro de 1948, diz em seu artigo $\mathrm{XXV}$, parágrafo $10^{\circ}$ :

"Todo o homem tem direito a um padrão de vida capaz de assegurar a si e à sua familia, saúde e bemestar, inclusive alimentação, vestuár.lo: babitação, culdados médícos, e os serviços sociais indispensáveis, e äireito à seguranç̃ em caso de desemprfgo, doença, invalidez, velhice e outros casos de perda dos meios de subsistência em clreunsiancias fora de seu controle".

e no parágrafo $2 .^{\circ}$ :

"A maternidade e a infància têm direito a cuidados e assisténcia pspeciais. Todas as crianças nascidas dentro ou fora do matrimônio, gozarão da mesma proteção social".
A proclamação desta declaração pela ONU, deu motivos e bases a praticamente todos os paises, principalmente os dos Continentes Europeu e Americano, para iniciar reformulaçōes legislativas e elaboração de novos programas assistenciais. Originou inclusive uma outra declaração universal, chamada: "Declaração Universal dos Direitos da Criança", que pretendem dar subsídios para que os governos pudessem assegurar melhores condiçōes de vida às crianças, pois por motivos sócio-culturais em diversos países do mundo, um número incontável de crianças permaneciam até então sem direito à assistência, excluídas de programaçōes governamentais, enfim sem lugar definido na sociedade. Impunha-se que a população Materno-Infantil fosse especialmente atendida, protegida da mentalidade egocêntrica $\mathrm{e}$ imediatista do mundo moderno.

Conhecer, procurar cumprir e defender os direitos da Criança é dever de cada um. Se toaios os indivíduos co-

- Trabalho apresentado na Semana de Enfermagem - 1979 - ABEn - Seçáo RS.

* Enfermeira da ABEn - Seção do Rio Grande do Sul. 
TROGER, A.L.M. - A saúde da gestante Rev. Bras. Enf.; DF, 32 : 255-258, 1979.

laborassem neste sentido, os nossos descendentes poderiam esperar, por certo, um futuro mais promissor daquele que o mundo atual lhes reserva.

A OMS frisa no preâmbulo de sua constituição que "o gozo do mais alto nível de saúde que se possa conseguir, é um dos direitos fundamentais do homem. Os governos têm responsabilidade em relação à saúde de seu povo, a qual só pode ser cumprida mediante a adoção de medidas sanitárias e sociais adequadas".

Levando em conta as recomendações da OMS/OPS, a Declaração Universal dos Direitos do Homem e a da Criança, o Governo Federal participou da elaboraçāo do Plano Decenal para as Américas (1971-1980), iniciando com o $2 .^{\circ} \mathrm{Pla}-$ no Nacional de Desenvolvimento as ações em prol da assistência MaternoInfantil.

Desde então são desenvolvidos programas específicos de assistência médico-sanitária, que objetivam a redução da morbilidade e mortalidade maternoinfantil.

Pela sua magnitude o Plano envolve além das ações governamentais, com a colaboração de todos os profissionais de saúde, também as entidades privadas, enfim toda população, a qual deve contribuir ativamente nas ações de melhoria da saúde pública.

E inegável a importância dada à proteção da população materno-infantil, aliás um grupo, que segundo estatísticas de 1970 , significa $69,58 \%$ da população brasileira. Contudo, ainda se trabalha com uma população cuja motivação se orienta mais para os aspectos curativos que preventivos de doenças. Assim verifica-se que em nossa sociedade um número relativamente grande de gestantes procura atendimento médico durante o parto, valendo-se das facilidades que a Previdência Social lhes oferece, não ocorrendo o mesmo no período pré-natal ou intergestacional, quando a procura dos serviços de saú- de para fins de orientação é praticamente nula.

Segundo a OMS/OPS (1974), as Unidades de Assistência Primária, devem, para obter melhor rendimento e maior abrangência das açōes de saúde, estar capacitadas para desenvolver um programa básico de saúde. Inclui este programa tarefas especificas em diversas áreas de ação, principalmente nas de Epemiologia e Assistência Materno-Infantil, dando ênfase à Educação para saúde e Nutrição. Esta recomendação da OMS/OPS desencadeou em 1975, através a Lei 6.229, uma série de programas de saúde, principalmente os de alcance coletivo como combate e controle das grandes epidemias, proteçāo maternoinfantil, alimentação, promoção da rede nacional de laboratórios de saúde pública com a construção e reaparelhamento das Unidades Sanitárias. Com esta lei portanto, realizou-se mais um passo gigantesco em prol da melhora na Assistência Materno-Infantil.

Mas o que se compreende sob ações de assistência Materno-Infantil?

De acordo com a V Conferência Nacional de Saúde seria a "assistência contínua e periótica da mulher durante $o$ período de gravidez, parto e puerpério, como o diagnóstico e tratamento de intercorrências para dar ao concepto condições físicas, psíquicas e sociais para crescer e se desenvolver".

Visto que a saúde do feto e da criança dependem muito mais da saúde pré e interconcepcional da mãe do que se supunha até há pouco, esta assistência deve ser objetivada por toda equipe de saúde, como uma nova área de atuação, cabendo à Enfermagem uma grande parte da mesma, principalmente no que diz respeito à Educação para Saúde.

A Educação para Saúde é talvez a atividade mais complexa que deve ser executada, pois não visa somente dar informações de saúde, mas originar mudança de comportamento, no caso, especificamente de mulheres em período pre- 
concepcional, gestantes ou mães, para obtenção de melhores níveis de saúde.

De acordo com estudos realizados, seguir recomendações médicas e adotar comportamentos novos de natureza preventiva, são atuações mais freqüentes em populaçōes de melhores níveis sócioeconômicos, se bem que mesmo nestes níveis ocorrem atitudes que são frontalmente contra as recomendações oficiais de prevenção à doença como por exemplo: fumar e tomar bebidas alcoolicas durante a gestação e mesmo fora da mesma, não escovar os dentes após as refeições, comer alimentos pesados em excesso, etc.

Do mesmo modo torna-se difícil obter das mulheres em idade fértil adoção de medidas que visem evitar e controlar complicações gravídicas. Sempre há riscos gravídicos que não podem ser previstos ou mesmo evitados, mas sendo que grande parte dos riscos podem ser detectados precocemente e contornados através de tratamento adequado ou educação para saúde, as gestantes devem se conscientizar que é indispensável procurar os locais de assistência pré-natal já no $10^{\circ}$ trimestre da gravidez.

As visitas de controle posteriores devem ser repetidas com pontualidade conforme aprazamento realizado e é muito importante que a gestante siga as orientações dadas. Isto se refere especialmente a mulheres de risco gravídico detectado. Ocorre no entanto que justamente estas gestantes é que menos comparecem aos serviços de saúde, o que constitue por si um problema a ser removido, ao menos em parte, pela Educação para saúde desde a época pré-concepcional.

De acordo com a publicação n..$^{12}$, série D, n. ${ }^{\circ}$, da Secretaria do Estado da Saúde de São Paulo, o comparecimento da gestante, que procura os Serviços de Saúde Estatais, à consulta médica, é em média, de apenas 2 a 4 vezes durante a gestação, recebendo nesta ocasião apenas mínimo de orientação, o que produz nada ou quase nada em mudanças de atitude. Outra tendência que se observou é a das mulheres com muitos filhos tenderem a não procurar os serviços pré-natais, alegando experiência anterior, falta de tempo, ou mesmo por rejeitarem a gestação. No entanto sabe-se que a nati-mortalidade aumenta consideravelmente após a $5 .^{a}$ gestação, como também os perigos e freqüência de outros acidentes gestacionais, ocorrências estas que, junto com outras resultantes de fatores sócio-biológicos, pōem em perigo a integridade física, psíquica e social da gestante e do feto, sendo portanto classificadas como "riscos gravídicos", e passíveis de atenção especial de toda Equipe de Saúde.

Por causa destes "riscos gravídicos" o planejamento familiar deveria fazer parte dos assuntos abordados nos programas de Educação para Saúde, já durante a época gestacional, quando a mulher se dispõe a procurar os serviços de saúde com mais facilidade do que na época intergestacional.

Supervisionar e manter a normalldade da gestação, evitar e controlar os riscos, dar apoio e educaçāo para saúde a pacientes através de um programa de exames, avaliação periódica da gestaçāo, tratamento e educação contínua sāo as metas a serem atingidas, através açāo conjunta dos componentes da equipe de saúde, e transformar a gestaçāo e parto em um processo normal sem perigo para a mãe e o bebê deve ser sempre o objetivo final visado mas ações de saúde.

A prontidão com que a mãe recebe tratamento e ensinamento são fatores determinantes na obtenção de resultados positivos, portanto é necessário que o pessoal de enfermagem realize uma avaliação conjunta da personalidade de cada paciente para determinar as medidas educativas de maior impacto que devem ser adotadas pela equipe.

Nestas atividades, as ações de enfermagem de maior significado são: Consulta de enfermagem, com levantamento das necessidades básicas sentidas pela paciente, complementação de consulta médica com feed-back, educação 
TROGER, A.L.M. - A saúde da gestante. Rev. Bras, Enf.; DF, 32 : 255-258, 1979.

individual ou em grupos de gestantes, nutrizes, mães e mesmo adolescentes através de entrevistas, palestras, demonstrações e dramatizações ou discussões em grupo; abordando sempre temas como por exemplo: evolução da gestação, parto, puerpério, desenvolvimento do bebê, higiene alímentar do adulto e da criança, economia do lar, higiene individual, reprodução e planejamento familiar, e toda uma série de assuntos que podem esclarecer dúvidas e melhorar o estado de saúde, situação social ou estado psíquico do grupo interessado.

Vimos que a atuação da enfermeira é de enorme responsabilidade e abrange iima gama de conhecimentos científicos e práticos, que lhe permitam assumir es- tas funções além de tantas outras que deve abraçar quando em pleno exercício profissional. Ocorrem ocasiōes em que a exigüidade de tempo, o acúmulo de tarefas impedem que a enfermeira cumpra na íntegra todo o programa previsto, mas sabemos que o trabalho em equipe está se tornando cada vez mais aperfeiçoado e indispensável, para que um possa assumir, ao menos parte das funções do outro quando este estiver impedido. Este fato está ocorrendo na equipe de saúde onde tanto técnicos como pessoal auxiliar procuram se completar mutuamente, e atuando unissonamente junto à gestante, à puérpera, à nutriz, ou à mãe para obter melhores condiçōes de saúde desta e da criança, da qual, em última, depende o futuro do país. 